\title{
The Calibrating System of Fluid Flow Meter based on Lab VIEW
}

\author{
Jixin Zhou \\ Faculty of Electrical Engineering, \\ Tianjin Electronic Information Vocational Technology College, Tianjin, China \\ zhoujixin@126.com
}

\begin{abstract}
On the basis of researching the fluid flow meter calibrating method and device, this paper has designed a set of flow meter calibrating system which based on LabVIEW software. It mainly introduces the hardware device, software control system and influence factors of precision test. The system use the software processing method for compensating the measuring error, improve the accuracy of system, and reduce the cost of system.
\end{abstract}

\section{Keywords-LabVIEW,flowmeter, calibrate ,commutator}

\section{INTRODUCTION}

In the industrial production, the flux is a parameter which is often detected. With the development of science and technology, the accuracy requirements of flow measurement are also getting higher and higher. In order to ensure accurate measurement, flow meter in before they leave the factory, using, and maintenance after using must be performance testing or calibrating. This paper introduce a flow meter calibrating device which be used in factory and have lower manufacturing cost, higher working efficiency.

\section{OVERALL DESIGN}

We have a way to test and Calibrate flow: We inject liquid to a container continuously with a steady flow of $\mathrm{Q}$, and write down the accurate starting time T1and stop time T2. At the same time, we accurately measure liquid number( Qm or Qv ) accumulated in container of $\triangle \mathrm{t}=\mathrm{T} 2$ - $\mathrm{T} 1$ interval, then you can calculate the average flow. To achieve this process a set of device includes: a device used for liquid storage ; a device

This control system use industrial computer equipped with multifunctional data card. This type of control can be shared by multiple calibration pipeline. It use the industrial control computer as upper machine, multi-function data card and a simple control circuit board as lower machine. It through the interactive information between the data acquisition card and a circuit control plate control actuator and collect the input signal. It deposit, analyse and compute collection of data by industrial control computer, then give the output results. The control system based on LabVIEW software has a friendly interface, and its operation and monitor system is more convenient. It also have lower cost and higher reliability. used to ensure liquid flow is stabilization in pipe test section ( the liquid flow pipeline including the straight section for installing flow meter ); a work containers and some temperature transmitter used to measure liquid quantity through the flow meter in a certain period of time; some water media for emptying or weighing container and pipeline; some drain valve used to return water media to the storage device; some commutator used to regulating the flow of fluid in a test pipe, so as to ensure the flow calibrating device working according to a predetermined program; and a control and management system used to measuring time interval and the flow meter pulse number, ensureing the liquid quantity time、 output signal of be detected flow meter are synchronous, also have automatic calibration, data storage, print statements and other functions .The specific mechanical structure as shown in figure 1.

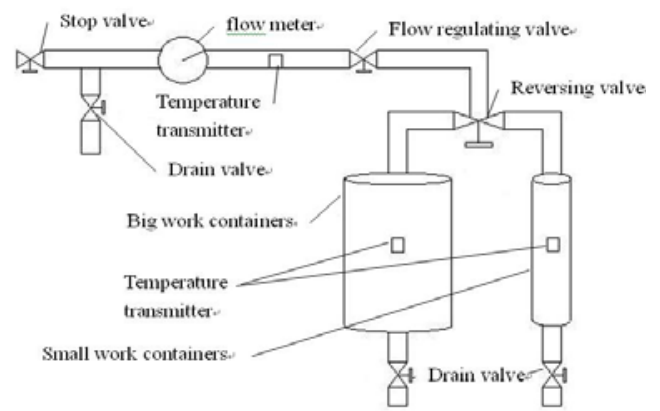

Figure 1. Mechanical structure drawing

\section{HARDWARE DESIGN}

The calibrating system needs to monitor temperature signal, capture output signals of be calibrated flow meter, control the Executive devices, and so on. Flow meter calibration system hardware device consists of: industrial control computer multi-function data card 、 conversion circuits 、 executive devices (drain valve, flow regulating valve, etc) 、flow meter 、 Temperature transmitter 、 and man-machine interactive equipment (keyboard, mouse and printing equipment etc.), some equipments used to providing the necessary power of the system itself and flow meter or other anti-jamming device which be used to ensure the reliable operation of the system. The system diagram as shown in Figure 2 . 
The multi-function data card can made the signals to the A/D conversion, D/A conversion, digital IO control, and sent the signal to the IPC in the last. It used the software to process data and complete hardware and computer interaction.

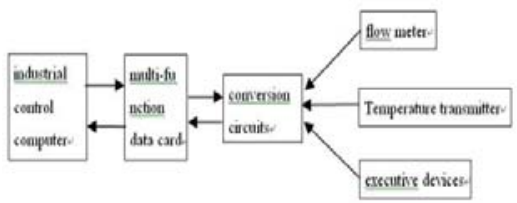

Figure 2. system diagram

\section{SOFTWARE DESIGN}

\section{A. Summary}

Flow meter Calibration is a tedious and complex work. In order to ensure the accuracy of collecting, output value of being calibrated instrument under each flow point must be calibrated repeated, which is bound to make use of the computer for automatic acquisition. However, traditional computer acquisition methods must write complicated hardware interface procedures and data processing procedures. Software system using the traditional method of setting up a computer can take up a lot of time in the development of the instrument. We take advantage of the virtual instrument which increasingly apparent advantage in the field of data acquisition to overcome the traditional acquisition methods defect.

In accordance with the requirements of the verification system, the system software is in modular structure. It made real-time data as the core to design many function module just like pipe set、 test、 data management and so on. It also is able to achieve real-time data display, have the settings to modify instrument parameters and some functions just like data analysis, data storage, error information display and so on. Friendly operator interface of the system implement guidance system structure and easy to be operated.

\section{B. Key technology}

For the control and regulation of the flow in the pipeline is a key part of the certification process. It can play a steady flow and compensate flow deviation. Here we use a method of automatically to control the flow. It adjusted the opening degree of the actuator automatically according to the set of flow points, using the method of successive approximation to stable the flow rate value in the test pipe. The specific operation is: First, it must set the opening range of the regulating valve and take an intermediate value as the opening degree of the regulating valve; then, it measure flow rate value at fast and compare the flow rate value with a desired flow rate value. The loop exits until achieving the verification accuracy or exceeding the cycle number of times.

\section{EXPERIMENT DATA AND ERROR ANALYSIS}

Based on analyzing the calibration principle and influence of the testing accuracy, we found that the system error from the error of the standard container or the timing error of sampling the flow meter which to be detected. The standard container error is accredited by specialized national metrology institute, so the error is to meet the requirements. Therefore, flow meter sampling time error is the main factor affecting the accuracy and reliability of the calibration system. The commutator is the only equipment which can appear the time error in the entire test process. We make use of flow meter verification method for commutator of verification. The verification method is as follows: We measure according to the flow meter's calibration method and record workload readings B11, the measurement time $\mathrm{t} 11$ and flow meter pulse number N11. We commutated commutator $m$ times in substantially the same time and t11,in the same time, recorded scales or cumulative reading values B21, cumulative measurement time t21 and the accumulated pulse number N21 of flow meter. We repeated $n$ times of test and recorded $\mathrm{B} 1 \mathrm{i}, \mathrm{B} 2 \mathrm{i}, \mathrm{t} 1 \mathrm{i}, \mathrm{t} 2 \mathrm{i}, \mathrm{N} 1 \mathrm{i}$ and N2i $(\mathrm{i}=1,2, \ldots$ $\mathrm{n})$.Time interval:

$$
\Delta t_{i}=\frac{t_{1 i}\left(N_{1 i} / N_{2 i}-B_{1 i} / B_{2 i}\right)}{\left[\left(m B_{1 i} / B_{2 i}\right)\left(t_{1 i} / t_{2 i}\right)-N_{1 i} / N_{2 i}\right]}
$$

Test data as shown in the table:

As can be seen from the experimental results are negative, the experimental data show that the commutator error is adjustable. We can set the delay time of the timer / counter to adjust the measurement error. The measuring time interval was: $-0.007,-0.008,0.032$ at the point with the above-mentioned data measurement method. Some data in the data set is positive and another is negative indicating that the measurement error can not be re-adjusted. In accordance with the test procedures of various check flow meter test requirements, flow meter test system worked to meet the steady flow conditions. We computed and processed the flow meter test data are also in accordance with the national Verification Regulation of items. We made data linearity error and repeatability error analysis. The calculation results showed that this test system is in full compliance with the relevant requirements of the national verification procedures.

TABLE I TEST DATA

\begin{tabular}{|c|c|c|c|c|c|c|}
\hline \multicolumn{2}{|r|}{ Test status } & \multirow{2}{*}{$\begin{array}{l}\text { Does not } \\
\text { switch }\end{array}$} & \multicolumn{3}{|c|}{ switch (5 times) } & \multirow{2}{*}{$\begin{array}{c}\text { Time } \\
\text { interval }\end{array}$} \\
\hline & Test items & & 1 & 2 & 3 & \\
\hline \multirow{3}{*}{$\begin{array}{l}\text { Maximum } \\
\text { flow point }\end{array}$} & measurement time $\mathrm{t}(\mathrm{s})$ & 31.950 & 39.172 & 38.690 & 39.338 & -1.498 \\
\hline & pulse number N（N/L） & 2982 & 3547 & 3495 & 3553 & -1.496 \\
\hline & reading values $B(L)$ & 147.049 & 149.664 & 147.439 & 150.155 & -1.492 \\
\hline \multirow{3}{*}{$\begin{array}{l}\text { Minimum } \\
\text { flow point }\end{array}$} & measurement time $\mathrm{t}(\mathrm{s})$ & 235.100 & 237.132 & 239.641 & 240.714 & -1.225 \\
\hline & pulse number N（N/L） & 2964 & 2933 & 2952 & 2951 & -1.315 \\
\hline & reading values $B(L)$ & 148.424 & 143.843 & 144.595 & 144.595 & -1.302 \\
\hline
\end{tabular}




\section{CONCLUSION}

The system based on IPC as a core. It was designed in accordance with the basic theory of the flow test system and the test function to achieve. Verification system acquiring the input signal and controlling the output signal is achieved through the interaction between multi-function data acquisition card and control board. The IPC in the verification process have automatic collection, processing test data, print out the test results and other functions. System software in accordance with the requirements of real-time design, based on functional decomposition, study test software structure, flow diagram of the main program and each function module descriptions and flow charts. As a metrological verification device, the accuracy is one of the most critical indicators. We analyzed the various factors that affect the test accuracy, and focused on the greater impact on the commutation time error and simultaneous measurement of accuracy. The experimental results show that the test system is feasible, both technically and economically has a relatively high superiority.

\section{REFERENCES}

[1] Horritt,Matthew.Development and testing of a simple 20 finite volume model of such-critical shallow water flow.International Journal for Numerical in Fluids.2004,44(11):1231 1255

[2] T.T.Espina,P.I.Osella.An Intelligent Ultrasonic Flowmeter for Improved Flow Measurement and Flow Calibration Facility.Instrumentation and Measurement Technology Conference. 2001,3:1741 1746

[3] Wright,J D.Laboratory Primary Standards in Flow Measurement:Practical Guides for Measurement and Control,Spitzer,D.W.ed,The Instrumentation,Systems, and Automation Society Research Triangle Park North Carolina,2001,731 760

[4] J.Hemp.A technique for low cost calibration of large electromagnetic flowmeters.Flow Measurement and Instrumentation.2001,12(2):123 134

[5] Miau J J,Wu.cw.A study on signal quality of a vortex flowmeter downstream of two elbows out-of-plane.Flow measurement and instrumentation,2002,13(3):75 85 